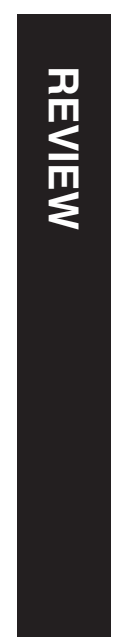

\section{5th RCOphth Congress, President's Session paper: 25 years of progress in surgical training}

L Benjamin

\begin{abstract}
Surgical training in ophthalmology has altered significantly over the last 25 years as a result of changes in technology, teaching methodology, and the recognition of the need for better structure and supervision. Along with this have evolved changes in curriculae and also in service delivery of our rapidly advancing specialty. Initial abandonment of time-based training has now reached the point of a slightly uneasy combination of a time- and competency-based structure, which will find firmer foundations in the near future. Simulation training and recognition of time spent in practising surgical skills will be important issues for future training programmes.

Eye (2014) 28, 1060-1065; doi:10.1038/eye.2014.143; published online 4 July 2014
\end{abstract}

Department of Ophthalmology, Stoke Mandeville Hospital, Aylesbury, UK

Correspondence: L Benjamin, Department of Ophthalmology, Stoke Mandeville Hospital, Aylesbury, Buckinghamshire HP21 8AL, UK

Tel: +44 (0)1296 315034;

Fax: +44 (0)1296315037

E-mail: Larry.benjamin

@btopenworld.com

Received: 12 February 2014 Accepted: 14 April 2014

Published online:

4 July 2014

Previously presented at the 25th anniversary congress of the Royal College of Ophthalmologists May 2013.
At the time of this presentation I still occupied the position of Chairman of the Education Committee at The Royal College of Ophthalmologists and was the senior vice president. This gave me a unique opportunity to examine what has changed in surgical training in the last 25 years, as at the beginning of this time period I was still in training and at the end I was chairing the Education Committee, which was responsible for the training curriculum, which in itself has changed dramatically.

One definition of training is 'The process of bringing a person to an agreed standard of proficiency by practice and instruction'. One of the important issues arising from this definition is how we select people into training and, before that, how we select people into medical school. Clearly, the issue of selection into medical school is a very broad one and as medicine (with a small ' $\mathrm{m}$ ') covers so many different specialty types we can afford to select very different people into training with the prediction that if some are not suitable for craft specialties they will be able to find other areas that interest them and, likewise, those not interested in craft specialties will have a wide variety of other opportunities from which their ultimate career path can be selected.

In recent years selection into ophthalmic training has been carried out centrally with a once-a-year selection process run by the Severn Deanery with representatives from all areas of the United Kingdom. Rather than basing selection on a single half an hour interview, preceded by CV-based shortlisting, the current process aims to assess various aspects of an applicant's character and achievements, as well as commitment to the specialty. This is being continually refined and hopefully it gives us a fairer selection process on which the final decision to select is made.

\section{Training 25 years ago}

In 1988 there was a split between Senior House Officer (SHO), Registrar, and Senior Registrar (SR) posts. Each was competitively interviewed and the average time spent as an $\mathrm{SHO}$ was 4 years, which was twice that required by the Faculty of Ophthalmology. Examinations were split into primary FRCS, diploma in ophthalmology, which included refraction, and a final examination, which was a combination of written and clinical examinations. Time spent in training was between 9 and 10 years on average.

\section{Record of surgical training}

Looking at my own surgical logbook from 1988, analysis shows that I was carrying out $\sim 30$ ophthalmic procedures per month, of which on average six or seven were emergencies, including retinal detachment repairs and the usual spread of trauma and postoperative 
complications. This was at a stage when I was an SR/clinical lecturer, and the majority of these cases were undertaken without supervision, or while supervising a junior. Interestingly my supervisor, Professor Anthony Bron, had signed me off in the back of this logbook to attend the College of Ophthalmologists Inaugural meeting in April 1989.

Comparing this handwritten logbook with today's electronic online automatic number-monitoring system with anonymised data shows today's system to be a far cry from the handwritten document made 25 years ago. The only real advantage of the handwritten logbook is that it shows a sample of my handwriting 25 years ago; however, it has none of the benefits of the modern system, which can analyse the inputted data in terms of type and number of different operations with respect to subspecialty, with automatic and cumulative totals and a range of other analytical features. All of these data can nowadays be collected by any electronic form, including smart phones, digital tablets, and computers, and can be inputted at source, which avoids the potential for data error.

\section{Calmanisation}

In 1993, Sir Kenneth Calman suggested that training should be re-orientated to a more European approach but with more structure. This led to changes in the terminology used and gave structure to the time spent in various posts. SHOs were still spending between 2 and 4 years in post, rotating between different jobs to get experience, and this in turn led to specialist registrar jobs, which were 5 years long, often followed by 1- or 2-year fellowship to subspecialise, which led to appointment as a consultant.

The current system has an expanded post-medical school training of 2 years at foundation year 1 and foundation year 2 (FY1 and FY2), followed by 7 years of subspecialty ophthalmic surgical training, during which time trainee-selected components are taken to gain subspecialty experience and, despite this, candidates often take on a year or two's fellowship to further subspecialise in preparation for a consultant post.

One of the other big differences between this new system and the older one is that the OST training years are based on a new curriculum, which has been developed by the College over the last several years. This is a competency-based curriculum of around 180 competencies, which are assessed by various methods, as opposed to almost 500 competencies in the old curriculum, which were more time-based rather than competency-based.

Interestingly, an article in the 2004 British Medical Journal $^{1}$ entitled 'No time to train the surgeons' suggested that more and more reforms were resulting in less and less time for training. In one particular surgical specialty, it was estimated that direct patient contact time had been reduced from $30000 \mathrm{~h}$ over the period of surgical training to $8000 \mathrm{~h}$ and that this was further reduced to $6000 \mathrm{~h}$ by the European working time directive, which stipulated that trainees were only allowed to work for a particular period of time before having enforced rest.

A survey carried out from St Mary's Hospital in the mid-2000s ${ }^{2}$ showed that the average number of cataract extractions performed by senior house officers was around 46 during their first 2 years of training, but that, excluding the three most experienced surgeons in the survey, the average number was actually 16 among the rest of the group. It was for reasons like this that new proposals for more structured, supervised, and competency-based training were made.

In August 2007, Modernising Medical Careers was introduced, along with the formation of the Postgraduate Medical Education and Training Board (PMETB). This body insisted on the development of a new curriculum, of which the Royal College of Ophthalmologists was the first to be accepted by PMETB. This new curriculum is very structured with competency-based training, giving rise to a number of acronym-related activities, such as case-based discussions, directly observed procedures (DOPs), clinical examinations (CEx), objective structured CExs (OSCEs), objective structured assessment of technical skills and so on. This involves a lot more structured work for the trainers who have had to undergo more formalised periods of training in how to teach, to ensure that this task of specialist accreditation, being competency and not time-based, is properly carried out.

There were fears expressed that the new curriculum would lead to a reduction in clinical curiosity, as people were chasing their competencies; however, David Cottrell, who wrote the curriculum with his very well-respected team at the College, has always said that the curriculum is not exclusive to what needs to be learned, it should not be used as an excuse not to learn other things.

\section{What is the ideal training?}

This should be a mixture of experiential learning, structured teaching, and experience (time!). Is there any evidence for this statement? A study that I was involved with, ${ }^{3}$ looking at global and task-specific scores in cataract surgery, using a five-point assessment system, showed quite clearly that the experience of a surgeon can be assessed by expert assessors watching video tapes of their surgery and that it was easy to differentiate those 
surgeons who had performed fewer than 50 cataracts, between those who had performed 50-250, and then again between those who had performed 250-500.

Above 500 no difference in the assessors' score was seen (Figures 1-3). This was true for task-specific scores, total scores, and global scores. This showed quite clearly that experience is an essential part of surgical training and this and other evidence convinced PMETB, who had originally asked all numbers to be removed from the curriculum, to allow the study guide, which accompanies the curriculum, to contain indicative numbers for cataract surgery. Most trainees in the United Kingdom exceed these numbers, which is reassuring. The tasks of the PMETB group have now been subsumed by the GMC, which has to assess, ratify, and approve changes to all medical curriculae.

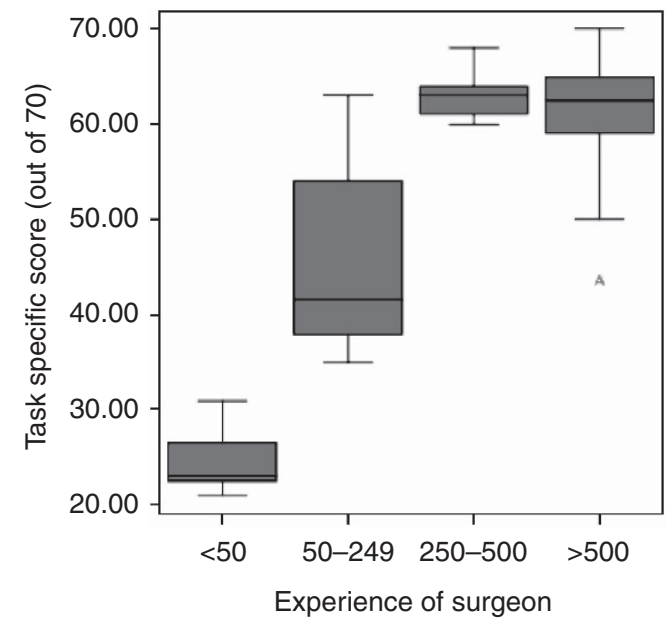

Figure 1 Showing the task-specific scores $v$ s experience of the surgeon group in terms of numbers of cataract procedures previously performed.

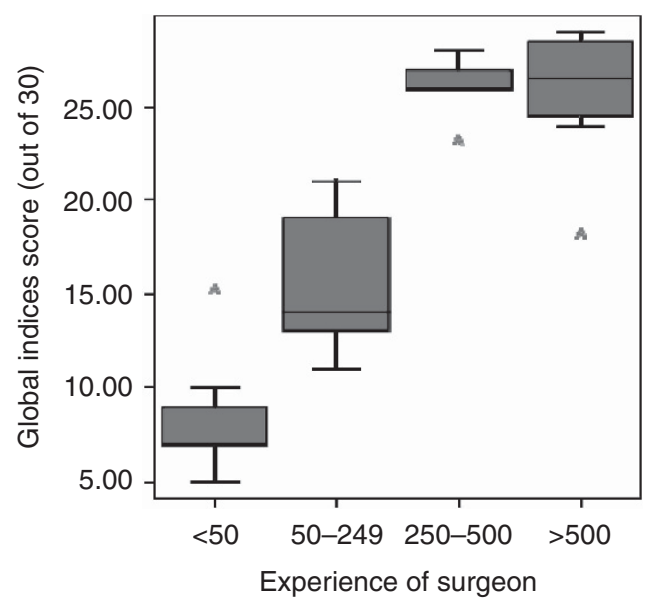

Figure 2 Global indices score $v$ s experience.

\section{The importance of practice}

In 2008 Malcolm Gladwell, a Canadian journalist, wrote a book called 'Outliers: The Story of Success' in which he suggests that it takes $\sim 10000 \mathrm{~h}$ to become an expert at anything demanding a cognitive process. Indeed, what he actually said was that it takes $10000 \mathrm{~h}$ to become an outlier - a phenomenon-and all the rest of us are experts. Calculating the approximate number of hours spent in training over an 8-year period at 10 sessions a week for 45 weeks a year comes to $14400 \mathrm{~h}$ with $\sim 10000$ of those being in direct patient contact. This was originally calculated to be $\sim 30000 \mathrm{~h}$ for general surgery and therefore there has been a significant reduction in the training time available. However, if we propose that the quality of training is now more structured, now with more formal training and assessment, then each hour in the training envelope and should hopefully be more productive.

Relating to the practice of surgical craft skills specifically, it is interesting that the actual time spent practising as opposed to performing the craft is very little. This is universal across the world in my experience, as very few centres have a formal skills laboratory set-up into which junior trainees can go to practise outside of their operating theatre-scheduled time. Figure 4 shows the current set-up at my own hospital in which a new surgical simulator is positioned next to a more traditional skills set-up with a bench top microscope, a dummy head, and artificial eyes, and between these two systems there is very little in terms of ophthalmology practical procedures that cannot be practised. Ideally, every training unit in the country would have a set-up like this, so that juniors and seniors alike can practise new techniques or new variations on old techniques. It is also very useful for people returning to work after a leave of absence, for assessment of certain DOPs, such as corneal

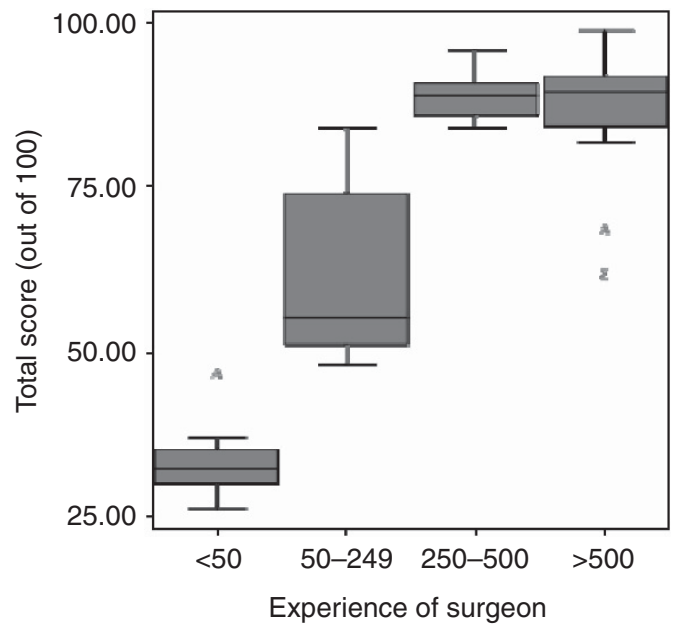

Figure 3 Total score $v s$ experience. 


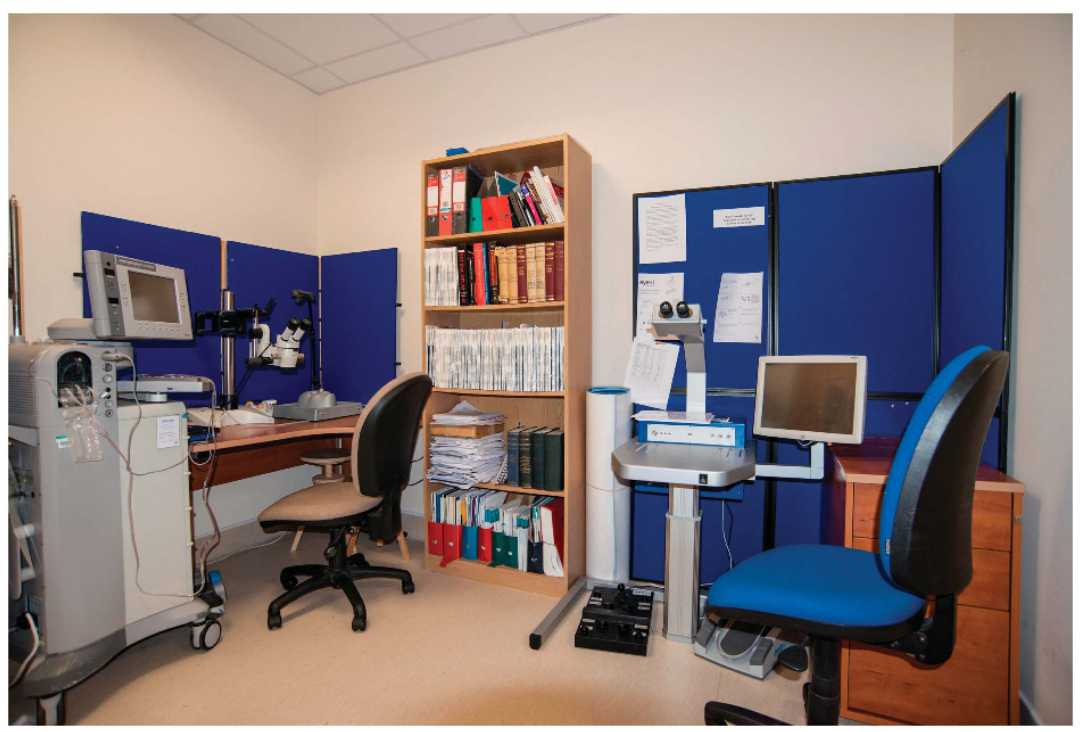

Figure 4 Traditional wet-lab station and simulator for trainees to practise at Stoke Mandeville Hospital.

glueing and penetrating injury repair, and may also be useful for things such as revalidation in the future. This set-up costs approximately $£ 120000$ but will last for many years and will serve many trainees, and the fact that the total cost of damages for ophthalmic litigation between 1995 and 2006 was £11 million alone would render this set-up a cost-effective solution for each training unit to have. Indeed, the driver for such a facility should be patient safety and better outcomes, regardless of litigation; however, the litigation costs are such that it makes this sort of investment very worthwhile.

The College runs a range of basic and more advanced microsurgical skill courses to facilitate this sort of practice and it gives trainees an idea of what to practise; however, it is incumbent upon the training units to put the facilities into place so that practice can take place regularly and frequently in the work place.

Simulation is a very good way of providing this practice and there are a range of products available that allow trainees to practise in the work place, which range from the very basic, such as practising capsulorhexis on a piece of cellophane stretched over a drinks can (Figure 5), to the College designed skills board and skills head with plastic eyes (Figure 6), to the recently introduced Kitaro kit, which allows wet and dry lab practice for cataract surgery (Figure 7), to the Eyesi VR magic eye surgical simulator, which is an advanced virtual reality simulator, allowing training similar to that which pilots receive on a flight simulator. The cost need not be high; however, very few units make use of these facilities for their juniors to practise on a regular and frequent basis. The simulators are improving and there are approximately 20 virtual reality simulators around the country; however, as stated previously, there are various forms of simulation that need not be expensive and trainees need to take advantage of the systems that are available to encourage them to develop their surgical craft skills more quickly. Simulation training does work and a paper by Spiteri et $a l^{4}$ showed quite clearly that the Eyesi virtual reality cataract simulator has been validated. Another paper by Belyea et $a l^{5}$ at the George Washington University showed that out of 592 operations, simulator-trained residents had shorter phaco times, lower percentage powers, fewer intraoperative complications, and a shorter learning curve.

This concept applies not only to trainees but also to ophthalmic consultants, and there is now good evidence that new techniques taken up by consultants also demonstrate a learning curve, such as that demonstrated by outcome analysis for survival of endothelial keratoplasties, showing that centres performing fewer than 15 procedures per year were twice as likely to fail as those performing 30 or more. The learning curve in this analysis was shown to be around 15 cases and as a result of this the College has introduced an endothelial keratoplasty course in which human eyes are used to practise their technique before people undertake the procedure for the first time. It is well established that learning and training is lifelong and applies to everybody and this should become part of the training culture.

\section{Summary}

Ideally, trainees should have a structured training programme/curriculum, time in the working week for training/supervision for all assessments. Each hospital department should have its own simulator and/or skills station and each trainee surgeon should practise each 

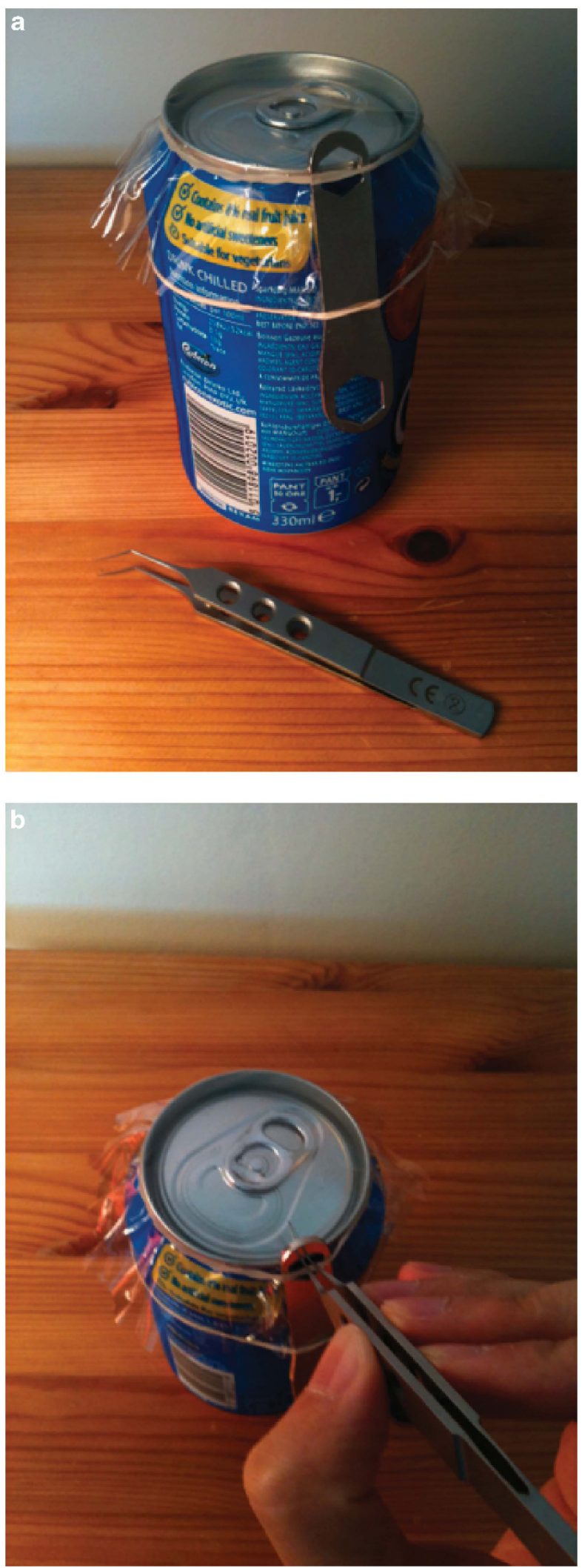

Figure 5 (a and b) Drink can with cellophane, (a) bike spanner and elastic band (b) used to practice capsulorhexis.
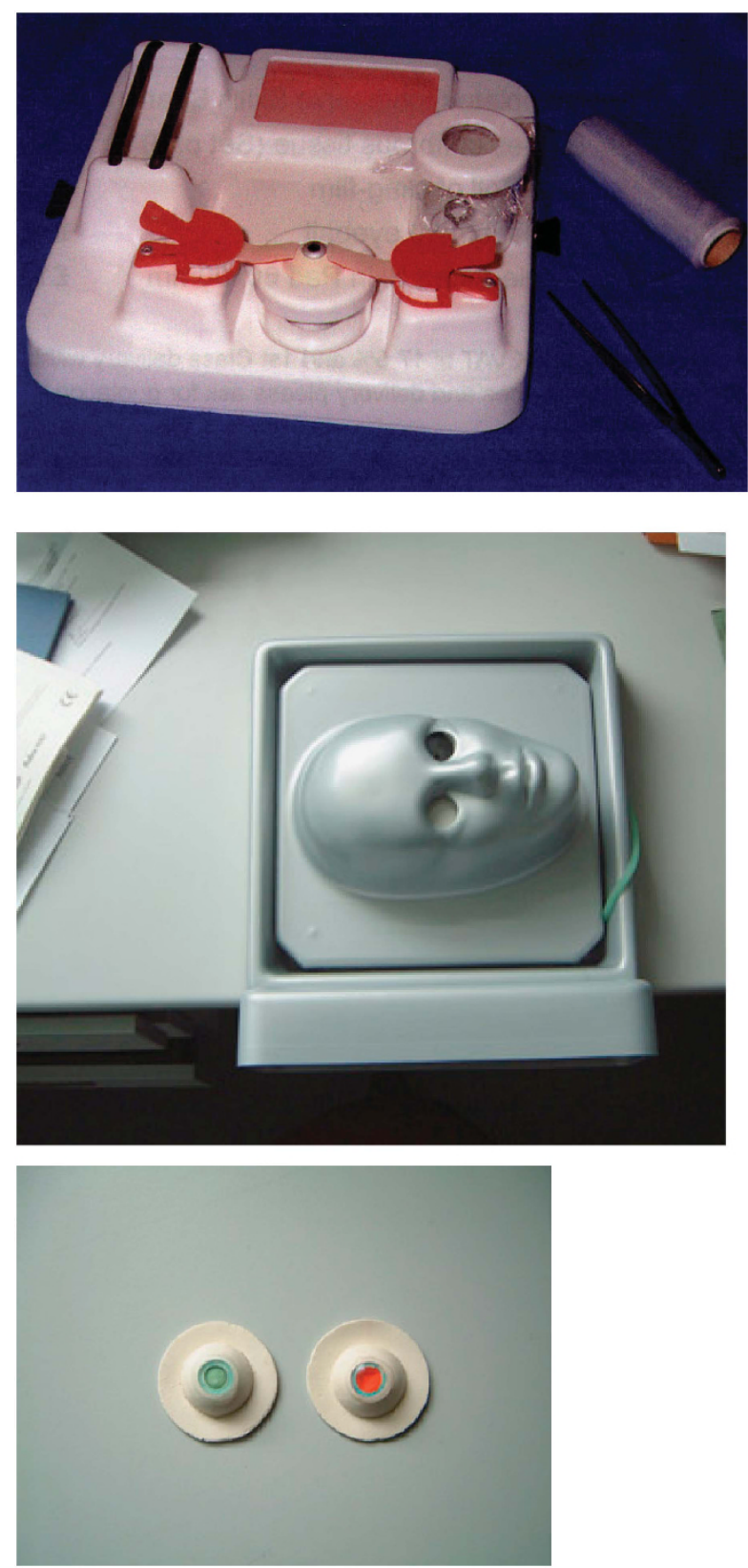

Figure 6 College skill board for practising capsulorhexis, suturing (including extraocular muscle procedures). College skill head used for practising phacoemulsification surgery with plastic eyes (below). Plastic eyes used for cataract and suture practice.

day in the skills centre. All surgery should be videorecorded and the trainees should review the various steps of the procedures they carry out. Further, at their annual review of competency and progression, greater time and importance should be devoted to these aspects to determine whether people should progress to the next stage of their training. Trainees nowadays do have a structured curriculum with structured learning outcomes 


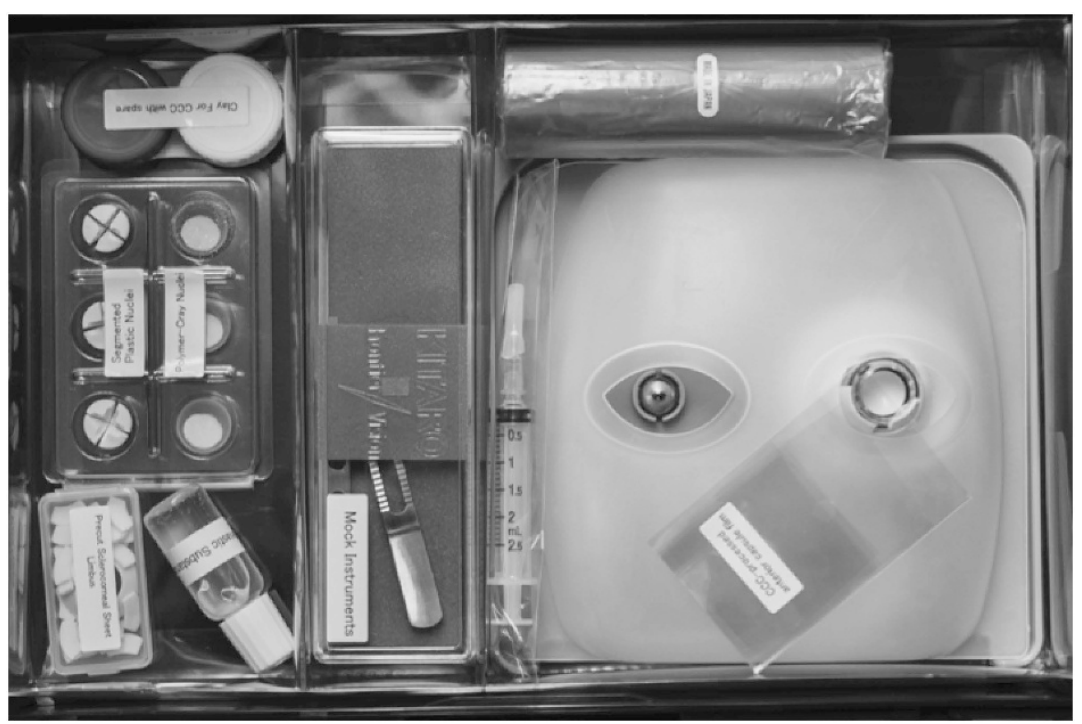

Figure 7 The Kitaro cataract simulation kit. Two versions are available for practising with a phaco machine and without. Nuclear fractis as well as capsulorhexis and phacoemulsification can be practised.

and they have competency-based learning. There also have to be fit for the purpose examinations (it is an education to see the depth of analysis that goes into each of the College examinations after it is taken to ensure that it has reached the required standard and that the questions posed are fit for purpose). There must be relevant teaching and there are many opportunities for self-directed learning, including videos on the internet and a whole host of other internet-based learning materials.

As far as the trainer is concerned, there are regular training-the-trainer courses, hosted by ours and other colleges, and other courses such as Educating Consultants. There is a lot of continuing professional development course material available, as well as access to degrees, such as Masters in Medical Education. Learning theory is much better understood and better taught and there is a lot more effort put into teaching theory, for example, the use of the four-step technique to introduce practical skills.

A lot of ground has been covered in the 25 years of the College's existence and this should make teaching, training, and learning more accessible, more relevant, and more fun. There is no doubt that new technology helps in the provision of this new training, but is of paramount importance is establishing a culture in which surgical training is viewed as important and given the relevant time, structure, and facilities.

\section{Conflict of interest}

The author declares no conflict of interest.

\section{References}

1 Chikwe J, de Souza AC, Pepper JR. No time to train the surgeons. BMJ 2004; 328(7437): 418-419.

2 Gibson A, Boulton MG, Watson MP, Moseley MJ, Murray PI, Fielder AR. The first cut is the deepest: basic surgical training in ophthalmology. Eye (Lond) 2005; 19(12): 1264-1270.

3 Saleh GM, Gauba V, Mitra A, Litwin AS, Chung AK, Benjamin L. Objective structured assessment of cataract surgical skill. Arch Ophthalmol 2007; 125(3): 363-366.

4 Spiteri AV, Aggarwal R, Kersey TL, Sira M, Benjamin L, Darzi AW et al. Development of a virtual reality training curriculum for phacoemulsification surgery. Eye 2014; 28: 78-84.

5 Belyea DA, Brown SE, Rajjoub LZ. Influence of surgery simulator training on ophthalmology resident phacoemulsification performance. J Cataract Refract Surg 2011; 37: 1756-1761. 